\title{
Methods of Rating the Effectiveness of Cultural Institutions in the Territorial Context
}

\author{
Nataliya Malshina ${ }^{1, *}$ Galina Chernyshova ${ }^{2, a}$ Anna Firsova ${ }^{3, b}$
}

\author{
${ }^{1}$ Department of Humanitarian Disciplines, Saratov State Conservatoire named after L. V. Sobinov, ORCID 0000-0003- \\ 1632-538X, Saratov, Russia \\ ${ }^{2}$ Department of Discrete Mathematics and Information Technology, Saratov State University named after N. G. \\ Chernyshevsky, ORCID 0000-0002-6464-0408, Saratov, Russia \\ ${ }^{3}$ Department of Banking Sector, Saratov State University named after N. G. Chernyshevsky, ORCID 0000-0002-8906- \\ 6326, Saratov, Russia \\ aEmail: cherny111@mail.ru \\ bEmail: a.firsova@rambler.ru \\ *Corresponding author. Email: malsnataliya@yandex.ru
}

\begin{abstract}
The article implements the main tasks: development ranking of the regions in the sphere of the cultural industry and Russian regions rating creation to estimate the degree of integration and effectiveness of the cultural industry development in every region; developing of new estimates of the activities of the cultural industry and mathematical instruments for evaluating its comparative effectiveness (index number creating); developing of criteria, integrated indices, instruments, indices and application algorithm; development of a regional classification methodology, creation of a development ranking map of Russian regions in the sphere of the cultural industry and Russian regions rating creation. To evaluate the index of effectiveness, an undirected variable-scale model is proposed, which allows both a reduction in inputs and an increase in outputs for an ineffective DMU to achieve an efficient frontier. It is proposed to use a method based on information entropy to construct an aggregated index. Evaluation criteria were chosen in such a way as to comprehensively reflect the resources available to cultural institutions and to characterize the targeted results of activities according to their structural characteristics, to have comparable quantitative values, to be available in official sources. As a part of the proposed approach, the regional assessment of the cultural industry at the first level is carried out in three directions (theaters, museums, concert organizations and independent groups). The data for 78 regions of the Russian Federation were normalized and brought to a unified scale. As a result of obtaining a numeric evaluation of the integrated index of the effectiveness of the cultural industry, it is possible to classify Russian regions by allocating several groups. The task of visualization of the obtained results is solved by constructing a map of Russian regions ranking in terms of cultural institutions effectiveness. The author's method can be used by regional authorities in evaluating and planning the socio-economic development of the region and the development of the regional economy as well as in making managerial decisions in the sphere of cultural management.
\end{abstract}

Keywords: culture industry, theatres, museums, libraries, the development rating of the culture industry in

Russian regions

\section{INTRODUCTION}

The importance of culture for all fields of activity of the state and society has long been recognized and has

*Fund: The reported study was supported by Russian Foundation for Basic Research, project "Development of organizational, economic and financial mechanisms of support and strategic development of the cultural industry in the regions of Russia" № 19$010-01004 / 20$ never been questioned. The complex sectoral structure of the cultural sphere currently undergoes significant changes in accordance with the changes in the direction of development of postindustrial society. The sphere of cultural services in the most important sphere and constructing of a new model of the culture industry functioning that meets the modern economic and social challenges is an urgent scientific task [1] $]^{\mathrm{p} .188}$. 
However, at the present stage of the development of society the importance of the effectiveness of cultural sphere functioning can be fully substantiated in the economic and legal aspects. There is no doubt that the development level of the culture of society determines the effectiveness of the application of progressive ideas, innovations, new technologies, etc. The analysis of the level and evaluation of the comparative effectiveness of the Russian cultural sphere functioning in the territorial context offers opportunities for the innovative development of society as a whole, the improvement of the population quality of life, solving acute social problems as well as for identifying current problems of the society development, etc.

The object of this paper is the system analysis of the effectiveness of the Russian regional cultural institutions taking into account the evaluation of cultural institutions of various types by constructing a quantitative rating. The proposed methodology is based on the appliance of modern mathematical models, in particular Data Envelopment Analysis which provides a comprehensive evaluation of cultural institutions taking into account a differentiated set of input and output indices of activity.

The main tasks studied in the paper are:

- the development of rating methodology for cultural institutions of various types based on entropy approach;

- the constructing of effectiveness rating of cultural institutions for the regions of the Russian Federation;

- the classification of Russian regions based on quantitative evaluation of the cultural industry;

- constructing a map of Russian regions ranking in terms of cultural institutions effectiveness;

- impact evaluation of the culture industry on the economic development of Russian regions.

The study uses the method of integral rating analysis and the method of multidimensional ranking indices to evaluate the cultural industry in the regional context and for constructing a rating of effectiveness of regions based on the development level of various types of institutions. For evaluation of certain types of cultural institutions, it is proposed to use mathematical models of functioning environment Data Envelopment Analysis (DEA) that allow to obtain quantitative estimates of the technical effectiveness of complex objects functioning if there are several input and output indices of their activity. For constructing an integral rating, it is proposed to use an approach based on information entropy to obtain the value of weighing coefficients of selected indices.
For obtaining a true picture in comprehensive research practice on evaluation of development and effectiveness trends in the cultural industry basic methods of data collection were used including monitoring indices of cultural development, the analysis of statistics from Federal Service of State Statistics [2] and Culture Ministry of the Russian Federation [3].

\section{THEORETICAL ANALYSIS}

The main problem of solving theoretical issues of evaluation the effectiveness of the cultural industry is the lack of one common approach to allocate the structure and boundaries of the cultural sphere as well as standardized methods of analysis. For solving focused problems, precise definitions are used that take into account national ideas and traditions, the development paradigm of a particular state and public formation. The concept "cultural industry" [4] was originally used by scientists of Frankfurt School to describe the rapid development of theatre, music, cinema, dance, fine art, etc. Therefore, it seems necessary to analyze these important cultural sectors.

The concepts of "cultural industries" $[5]^{\mathrm{p} .85}$ and "mass culture" [5] $]^{\text {p.13 }}$ are differentiated in foreign studies. Cultural artifacts are now subject to the logic of profitability and capital accumulation with more systematic $[6]^{\text {p.100. }}$. The critical potential of intellectual culture is ... by conformist or "affirmative" product of the cultural industry which facilitate the adaptation of an individual to capitalism; to achieve this, various techniques are used: "standardization", "pseudoindividualization", "reaction mechanisms" [7] $]^{\mathrm{p} .94}$.

UNESCO defines cultural and creative industries as "sectors of organized activity whose main purpose is to produce or reproduce, promote, distribute and/or commercialize goods, services and activities of cultural, artistic of heritage origin" [8].

\section{THE METHODOLOGY OF THE STUDY}

The increasing popularity of the use of constructing instruments of an integral index for evaluation economic objects is caused by the obvious need of stakeholders (business, population, regional and municipal authorities, investors and others) [9] in comparable information on the level of effectiveness of the analyzed economic subsystem.

Constructing of rating estimates is used for monitoring, prognostics, management (monitoring of the current state of systems, detecting trends in system behavior, project planning and development of necessary control actions). The wide use of ratings as the method of evaluation by means of an aggregated index is due to the possibility of obtaining comparable results in the process of analyzing homogenous objects. 
There are many methods for calculating the integrated index, which can differ from each other by analyzed factors as well as by mathematical expression of the integrated index.

For constructing of a summary rating there is a number of different approaches: expert-point methods (indices evaluate the intensity of properties of various components, determining the index validity by experts), methods of rank statistics (the transition from quantitative characteristic values to ranks is possible if these values change linearly i.e. uniformly), topometric methods (taking into account the proximity of regions according to the compared indices to the standard region, the choice of a standard), multidimensional scaling methods (allow to transit from quantitative values of features characterized by heterogeneity to qualitative analogs and make all indices commensurate) [10].

Methods for constructing rating estimates include such stages as forming a set of evaluation criteria rationing (standardization) of selected indices, choosing a mathematical model for constructing an integrated index. Each of these components of the technique involves determining parameters of the model by an expert method that makes the ranking process subjective.

The proposed rating methodology is based on a hierarchical system of evaluation indices and is a synthesis of three separate blocks corresponding to separate areas of activity of cultural institutions for each of which the evaluation is carried out: theatres, museums, concert organizations, independent groups. According to the three blocks that make up the final estimate, the rating is calculated in accordance with the index of effectiveness calculated using DEA. The final (integral) rating is a generalization of ratings by individual blocks.

DEA is a multidimensional nonparametric method of measurement of relative effectiveness of a set of objects, the so-called decision-making units (DMU) described by a set of the variables operating as inputs and outputs in the described model [11]. The DEA model allows multiple inputs and outputs at the same time. The DEA is based on the solving of a linear programming problem to maximize DMU outputs with a given number of resources (inputs) or to minimize resources (inputs) with a given level of outputs. The concept of technical effectiveness is seen as the ratio of weighted outputs variables corresponding to DMU results to weighted input variables corresponding to DMU resources used. DMU that have maximum efficiency values are selected and a piecewise linear function, the so-called efficient frontier is constructed. Those DMU that receive the highest estimates are at the frontier and become standards for other DMU in the sample.
There are currently several different types of DEA model that enable to take into account specific factors such as parameter prioritization, economies of scale, risks, etc. [12].

For evaluation of index of effectiveness, an undirected variable-scale model is proposed which enables both reduction in inputs and increase in outputs for inefficient DMU to achieve efficiency frontier. For $D M U_{k}$ model is:

$$
\begin{aligned}
& \min \frac{1-\alpha}{1+\beta} \\
& \sum_{j=1}^{n} x_{i j} \lambda_{j} \leq(1-\alpha) x_{i k}(i=1, \ldots, m)
\end{aligned}
$$

$$
\sum_{j=1}^{n} y_{r j} \lambda_{j} \geq(1+\beta) y_{r k}(r=1, \ldots, s)
$$

(3)

$$
\begin{aligned}
& \sum_{j=1}^{n} \lambda_{j}=1 \\
& \alpha, \beta, \lambda_{j} \geq 0(j=1, \ldots, n)
\end{aligned}
$$

Technical index of effectiveness $T E$ is defined as (1$\left.\alpha^{*}\right) /\left(1+\beta^{*}\right)$ where numerator $\left(1-\alpha^{*}\right)$ indicates the degree of decrease for inputs, denominator $\left(1+\beta^{*}\right)$ indicates the increase for outputs [13].

$D M U_{k}$ is considered effective when meeting the condition that the technical index of effectiveness is 1 , a similar $D M U_{k}$ is at the efficiency frontier. $D M U_{k}$ is considered ineffective when meeting the condition that the technical index of effectiveness is less than 1 which shows how much is the share of the possible productivity of the object.

The technical effectiveness values of TE calculated for different types of cultural institutions determine the values of partial indicators at the first stage of rating in accordance with task (1)-(4).

At the second stage for constructing an aggregated index, it is proposed to use the method based on information entropy. For constructing of a summary rating there is a number of different approaches: expertpoint methods (indices evaluate the intensity of properties of various components, determining the index validity by experts), methods of rank statistics (the transition from quantitative characteristic values to ranks is possible if these values change linearly), topometric methods (taking into account the proximity of regions according to the compared indices to the standard region, the choice of a standard), multidimensional scaling methods (allow to transit from quantitative values of features characterized by heterogeneity to qualitative analogs for standardization).

In information theory, entropy is a common measure of uncertainty [14]. When the difference in 
values for the evaluation objects for the same index is high and entropy is small, it shows that this index provides more useful information and the relative weight of this index is higher, and vice versa [15]. Such an effect can quantify the systemic effect of emergence. This approach is used to determine the integrated index based on a set of partial indicators: the weighted sum is calculated where the weights are information entropy values for a particular partial indicator.

The procedure of information entropy evaluation includes the following stages. Let us assume that a set of indices to describe a group of homogeneous objects is the matrix $X$ :

$$
\begin{aligned}
& X=\left(x_{i j}\right)_{n \times m}, \\
& i=1,2, \ldots, n ; j=1,2, \ldots, m ;
\end{aligned}
$$

where $x_{i j}$ is the value of the $j$-index for the $i$ object, $n$ is a number of objects, $m$ is a number of indices used in rating.

The first step is to obtain the matrix $R$ :

$$
\begin{aligned}
& R=\left(r_{i j}\right)_{n \times m}, \\
& r_{i j}=\left[\frac{\left(x_{i j}-x_{\operatorname{minj} j}\right) \cdot(N-1)}{x_{\text {maxj }}-x_{\operatorname{minj}}}\right]+1
\end{aligned}
$$

Where $r_{i j}$ is the value of the $j$-index for the $i$-object in categorical scale (the values are rounded up to a whole number by dropping the fractional part), $x_{\text {minj }}$ and $x_{\operatorname{maxj}}-$ are the range of changes in the values of the $j$-index, $n$ is a number of values in the categorical scale.

The information entropy value of the $j$-index $H j$ is defined from Shannon's equation:

$$
H_{j}=\sum_{k=1}^{N} p_{k j} \ln \left(\frac{1}{p_{k j}}\right), j=1,2, \ldots, \quad m,
$$

Where $p_{k j}$ is the probability (relative frequency in this case at the final number of categorical values of the index in the matrix $R$ ) of the $k$-value for the $j$-index in the matrix $R$ wherein the sum of all probabilities $p_{k j}$ for the $j$-index is $1: \sum_{k=1}^{N} p_{k j}=1$.

Thus, the entropy value $H j$ depends on the frequency of $k$ for the $j$-index in $R$.

The final aggregated indices $E_{i}, i=1,2, \ldots, n$ that were obtained based on $m$ partial indicators for the $i$ object are calculated as follows:

$$
E_{i}=\sum_{j=1}^{m} H_{j} r_{i j} \text {. }
$$

The normalized value of the final index $E_{i}^{*}$ can be used:

$$
E_{i}^{*}=\frac{E_{\mathrm{i}}}{\max _{\mathrm{i}} E_{\mathrm{i}}} \times 100 \%
$$

Based on (5)-(8) for each region, the final value of the integrated rating index $E^{*}$ is calculated.

\section{DATA FOR THE STUDY}

Certain requirements were taken into account when forming evaluation criteria to be monitored and managed. Indices were chosen in such a way as to comprehensively reflect the resources available to cultural institutions and to characterize the target results of activity according to their structural characteristics, to have comparable quantitative values and to be available in official sources. It should be taken into account that such a set of verifiable indices is quite limited in terms of their availability in statistical sources.

As part of the proposed approach, the regional evaluation of the cultural industry at the first level is carried out in three directions (theatres, museums, concert organizations, independent groups). These directions sufficiently reflect the most important aspects of the cultural institutions activity covering a significant part of the service market within the cultural industry. The information base of the study were data on the cultural industry of Russian regions in accordance with differentiated sets of indices for certain types of cultural institutions ("Table I"). Most of these indices are relative values. It enabled to take into account the economies of scale for different regions. This will avoid estimate distortion depending on population or territory of a region. The data were normalized and brought to the unified scale. 
TABLE I. EFFECTIVENESS EVALUATION INDICES FOR VARIOUS CULTURAL INSTITUTIONS BY DEA METHOD

\begin{tabular}{|c|c|c|}
\hline \multirow[t]{2}{*}{ Model } & \multicolumn{2}{|l|}{ Indices } \\
\hline & Inputs & Outputs \\
\hline \multirow[t]{3}{*}{ Theatres } & $\begin{array}{l}\text { The capacity of auditoriums and theatres venues for } 1 \text { resident of the } \\
\text { region, places/person. }\end{array}$ & $\begin{array}{l}\text { The ratio of the number of events to the number of } \\
\text { theatres in the region, units. }\end{array}$ \\
\hline & $\begin{array}{l}\text { The ratio of the number of theatre staff to the number of theatres in } \\
\text { the region, person. }\end{array}$ & \multirow{2}{*}{$\begin{array}{l}\text { Receipts of funds from business and other income- } \\
\text { generating activities for } 1 \text { resident of the region, } \\
\text { thousands rubles/person. }\end{array}$} \\
\hline & $\begin{array}{l}\text { Budgetary receipts to theatres for } 1 \text { resident of the region, thousands } \\
\text { rubles/person. }\end{array}$ & \\
\hline \multirow[t]{3}{*}{ Museums } & $\begin{array}{l}\text { Exposition and exhibition area and storage area for } 1 \text { resident of the } \\
\text { region, sq. m./person. }\end{array}$ & The number of expositions, units. \\
\hline & $\begin{array}{l}\text { The ratio of the number of museum staff to the number of museums } \\
\text { in the region, person. }\end{array}$ & \multirow{2}{*}{$\begin{array}{l}\text { Receipts of funds from business and other income- } \\
\text { generating activities for } 1 \text { resident of the region, } \\
\text { thousands rubles/person. }\end{array}$} \\
\hline & $\begin{array}{l}\text { Budgetary funds to museums for } 1 \text { resident of the region, thousands } \\
\text { rubles/person. }\end{array}$ & \\
\hline \multirow{3}{*}{$\begin{array}{c}\text { Concert } \\
\text { organizations } \\
\text { and } \\
\text { independent } \\
\text { groups }\end{array}$} & $\begin{array}{l}\text { The capacity of main and additional auditoriums for } 1 \text { resident of the } \\
\text { region, places/person. }\end{array}$ & $\begin{array}{l}\text { The number of events held at their sites and outdoor } \\
\text { events, units. }\end{array}$ \\
\hline & $\begin{array}{l}\text { The ratio of the number of concert organization staff and } \\
\text { independent groups and independent groups to the number of } \\
\text { concert organizations and independent groups in the region, person. }\end{array}$ & \multirow[t]{2}{*}{$\begin{array}{l}\text { Receipts of funds from business and other income- } \\
\text { generating activities for } 1 \text { resident of the region, } \\
\text { thousands rubles/person. }\end{array}$} \\
\hline & $\begin{array}{l}\text { Budgetary funds to concert organizations for } 1 \text { resident of the } \\
\text { region, thousands rubles/person. }\end{array}$ & \\
\hline
\end{tabular}

The data for 78 regions of the Russian Federation were used in the construction of rating due to the fact that the activity indices of cultural institutions for Moscow and St. Petersburg, the largest cultural centers, are anomalous for a sample of regions (when the indices are normalized, this leads to a significant loss of accuracy). In addition, the data on these indices were not available for a number of regions.

\section{THE RESULTS}

The process of testing the proposed methodology for the regions of the Russian Federation, the index of effectiveness values of cultural institutions at the regional level were calculated based on DEA models that were aggregated into the final index ("Table II"). The weighting factors are information entropy values (6) for three indices of effectiveness for certain activities of the cultural industry: $H_{1}=2.67 ; H_{2}=2.31$; $H_{3}=2.65$.

TABLE II. TECHNICAL EFFECTIVENESS EVALUATION AND THE FINAL EFFECTIVENESS RATING OF THE RUSSIAN FEDERATION

\begin{tabular}{|c|c|c|c|c|c|}
\hline \multirow[b]{2}{*}{$\begin{array}{l}\text { Rating } \\
\text { Item }\end{array}$} & \multirow[b]{2}{*}{ Region } & \multicolumn{3}{|c|}{$\begin{array}{l}\text { Technical Effectiveness for Various Types of } \\
\text { Cultural Institutions, } T E\end{array}$} & \multirow{2}{*}{$\begin{array}{c}\text { The Final } \\
\text { Effectiveness } \\
\text { Index } E^{*}, \%\end{array}$} \\
\hline & & Theatres & Museums & $\begin{array}{c}\text { Concert } \\
\text { Organizations and } \\
\text { Independent } \\
\text { Groups }\end{array}$ & \\
\hline 1 & The Nizhny Novgorod Region & 0.812 & 1 & 1 & 100.00 \\
\hline 2 & The Moscow Region & 0.839 & 0.896 & 1 & 98.55 \\
\hline 3 & The Stavropol Territory & 1 & 0.707 & 0.995 & 95.67 \\
\hline 4 & The Omsk Region & 0.766 & 0.767 & 1 & 89.42 \\
\hline 5 & The Sverdlovsk Region & 0.762 & 0.74 & 1 & 89.42 \\
\hline 6 & The Kamchatka Region & 1 & 0.426 & 1 & 89.05 \\
\hline 7 & The Kaliningrad Region & 0.858 & 0.471 & 1 & 84.81 \\
\hline 8 & The Republic of Bashkortostan & 0.448 & 1 & 0.989 & 84.11 \\
\hline 9 & The Chukotka Autonomous Region & 1 & 0.243 & 1 & 83.90 \\
\hline 10 & The Novosibirsk Region & 1 & 0.743 & 0.602 & 83.56 \\
\hline 11 & The Novgorod Region & 1 & 0.397 & 0.897 & 83.39 \\
\hline 12 & The Perm Territory & 1 & 0.468 & 0.814 & 82.87 \\
\hline 13 & The Kirov Region & 0.805 & 0.5 & 1 & 82.82 \\
\hline 14 & The Pskov Region & 0.82 & 0.476 & 1 & 82.82 \\
\hline 15 & The Rostov Region & 0.749 & 0.456 & 1 & 80.83 \\
\hline 16 & The Vladimir Region & 0.849 & 0.591 & 0.816 & 80.34 \\
\hline 17 & The Republic of Tatarstan & 0.686 & 1 & 0.624 & 80.22 \\
\hline
\end{tabular}




\begin{tabular}{|c|c|c|c|c|c|}
\hline 18 & The Republic of Sakha (Yakutia) & 0.515 & 1 & 0.777 & 78.19 \\
\hline 19 & The Tambov Region & 0.847 & 0.754 & 0.623 & 77.60 \\
\hline 20 & The Kemerovo Region & 0.648 & 0.741 & 0.805 & 77.54 \\
\hline \multirow[b]{2}{*}{$\begin{array}{l}\text { Rating } \\
\text { Item }\end{array}$} & \multirow[b]{2}{*}{ Region } & \multicolumn{3}{|c|}{$\begin{array}{c}\text { Technical Effectiveness for Various Types of } \\
\text { Cultural Institutions, } T E\end{array}$} & \multirow{2}{*}{$\begin{array}{c}\text { The Final } \\
\text { Effectiveness } \\
\text { Index } E^{*}, \%\end{array}$} \\
\hline & & Theatres & Museums & $\begin{array}{c}\text { Concert } \\
\text { Organizations and } \\
\text { Independent } \\
\text { Groups }\end{array}$ & \\
\hline 21 & The Sakhalin Region & 0.764 & 0.392 & 1 & 77.39 \\
\hline 22 & The Republic of Mari El & 0.573 & 0.537 & 1 & 76.58 \\
\hline 23 & The Lipetsk Region & 0.734 & 0.315 & 0.95 & 73.70 \\
\hline 24 & The Krasnodar Region & 0.661 & 0.377 & 1 & 73.42 \\
\hline 25 & The Saratov Region & 0.581 & 0.428 & 1 & 73.15 \\
\hline 26 & The Vologda Region & 1 & 0.492 & 0.542 & 73.00 \\
\hline 27 & The Trans-Baikal Territory & 0.639 & 1 & 0.438 & 72.31 \\
\hline 28 & The Leningrad Region & 0.77 & 0.201 & 1 & 72.24 \\
\hline 29 & The Chechen Republic & 1 & 0.677 & 0.339 & 71.97 \\
\hline 30 & The Tyumen Region & 1 & 0.311 & 0.66 & 71.79 \\
\hline 31 & The Samara Region & 0.808 & 0.175 & 0.948 & 70.53 \\
\hline 32 & The Khabarovsk Territory & 0.721 & 0.354 & 0.845 & 69.48 \\
\hline 33 & The Irkutsk Region & 0.749 & 0.519 & 0.67 & 68.72 \\
\hline 34 & The Kurgan Region & 0.624 & 0.956 & 0.408 & 68.61 \\
\hline 35 & The Komi Republic & 0.467 & 1 & 0.489 & 68.32 \\
\hline 36 & The Tula Region & 0.514 & 1 & 0.473 & 68.32 \\
\hline 37 & The Republic of Khakassia & 0.423 & 0.504 & 0.97 & 66.92 \\
\hline 38 & The Orenburg Region & 0.604 & 1 & 0.343 & 66.37 \\
\hline 39 & The Arkhangelsk Region & 0.68 & 0.256 & 0.886 & 66.04 \\
\hline 40 & The Voronezh Region & 0.794 & 0.308 & 0.698 & 65.81 \\
\hline 41 & The Altai Territory & 0.728 & 0.829 & 0.381 & 65.45 \\
\hline 42 & The Kostroma Region & 0.971 & 0.449 & 0.457 & 65.34 \\
\hline 43 & The Magadan Region & 0.702 & 0.019 & 1 & 65.10 \\
\hline 44 & The Tomsk Region & 0.583 & 0.178 & 1 & 64.56 \\
\hline 45 & The Bryansk Region & 0.937 & 0.402 & 0.416 & 61.38 \\
\hline 46 & The Ivanovo Region & 0.72 & 0.181 & 0.818 & 60.63 \\
\hline 47 & The Belgorod Region & 0.739 & 0.275 & 0.653 & 60.13 \\
\hline 48 & The Krasnoyarsk Territory & 0.565 & 0.425 & 0.7 & 59.31 \\
\hline 49 & The Republic of Dagestan & 0.158 & 1 & 0.55 & 58.36 \\
\hline 50 & The Udmurt Republic & 0.552 & 0.315 & 0.779 & 57.85 \\
\hline 51 & The Penza Region & 0.804 & 0.453 & 0.398 & 57.40 \\
\hline 52 & The Kaluga Region & 0.964 & 0.457 & 0.191 & 57.18 \\
\hline 53 & The Yaroslavl Region & 0.816 & 0.254 & 0.494 & 56.19 \\
\hline 54 & The Chelyabinsk Region & 0.532 & 0.337 & 0.71 & 55.87 \\
\hline 55 & The Primorsky Territory & 0.888 & 0.256 & 0.411 & 54.23 \\
\hline 56 & The Republic of Buryatia & 0.472 & 0.244 & 0.754 & 54.14 \\
\hline 57 & The Republic of Karelia & 0.663 & 0.325 & 0.562 & 53.92 \\
\hline 58 & The Amur Region & 0.75 & 0.352 & 0.386 & 53.69 \\
\hline 59 & The Volgograd Region & 0.54 & 0.498 & 0.477 & 53.12 \\
\hline 60 & The Kursk Region & 0.719 & 0.463 & 0.262 & 51.19 \\
\hline 61 & The Tver Region & 0.698 & 0.159 & 0.497 & 48.78 \\
\hline 62 & The Ulyanovsk Region & 0.553 & 0.584 & 0.277 & 48.66 \\
\hline 63 & The Astrakhan Region & 0.662 & 0.214 & 0.492 & 48.51 \\
\hline 64 & The Jewish Autonomous Region & 1 & 0.177 & 0.109 & 46.89 \\
\hline 65 & The Republic of Altai & 0.103 & 0.138 & 1 & 46.66 \\
\hline 66 & The Murmansk Region & 0.511 & 0.19 & 0.525 & 44.52 \\
\hline 67 & The Republic of Ingushetia & 0.032 & 1 & 0.272 & 44.51 \\
\hline 68 & The Oryol Region & 0.597 & 0.162 & 0.438 & 42.83 \\
\hline 69 & The Smolensk Region & 0.515 & 0.341 & 0.331 & 40.06 \\
\hline 70 & The Republic of Mordovia & 0.403 & 0.181 & 0.535 & 38.83 \\
\hline 71 & The Ryazan Region & 0.56 & 0.143 & 0.363 & 36.89 \\
\hline 72 & The Karachay-Cherkessia & 0.083 & 1 & 0.049 & 36.61 \\
\hline 73 & The Chuvash Republic & 0.273 & 0.2 & 0.472 & 34.59 \\
\hline 74 & The North Ossetia-Alania & 0.498 & 0.033 & 0.227 & 27.52 \\
\hline 75 & The Kabardino-Balkaria & 0.146 & 0.285 & 0.28 & 24.43 \\
\hline 76 & The Adygeya Republic & 0.171 & 0.044 & 0.43 & 23.48 \\
\hline 77 & The Republic of Kalmykia & 0.227 & 0.042 & 0.344 & 21.52 \\
\hline
\end{tabular}




\begin{tabular}{|l|l|l|l|l|l|}
\hline 78 & The Republic of Tyva & 0.313 & 0.069 & 0.188 & 19.57 \\
\hline
\end{tabular}

As leading regions with a high level of development of the cultural industry, the following regions can be indicated for designated activities: the Nizhny Novgorod Region, the Moscow Region, the Stavropol Territory, the Omsk Region, the Sverdlovsk Region, the Kamchatka Territory, the Kaliningrad Region, the Republic of Bashkortostan, the Chukotka Autonomous Region, the Novosibirsk Region, the Novgorod region, the Perm Territory, the Kirov Region, the Pskov Region, the Rostov Region, the Vladimir Region, the Republic of Tatarstan, the Republic of Sakha (Yakutia), the Tambov Region, the Kemerovo Region, the Sakhalin Region, the Republic of Mari El.

These regions because of the application of DEA methodology demonstrated the high effectiveness in the correlation of available resources and the results obtained from them, and accordingly higher values throughout the complex of certain activities of cultural institutions. In a resource-constrained environment of the region, the number of events and the amount of funds received from business and other incomegenerating activities allows to conclude that the functioning of territorial cultural institutions is effective. At the same time, the indices take into account the population of the region, which makes it possible to take into account the economies of scale when evaluating the committed budgetary funds and internal material resources of the region.

As a result of obtaining a numerical evaluation of the integrated index of effectiveness of the cultural industry, it is possible to classify Russian regions by allocating several groups depending on the values of the indicator ("Table III").

TABLE III. CLASSIFICATION OF REGIONS DEPENDING ON THE LEVEL OF CULTURAL INDUSTRY DEVELOPMENT

\begin{tabular}{|l|l|l|}
\hline \multicolumn{1}{|c|}{$\begin{array}{c}\text { The Level of Cultural Industry } \\
\text { Development }\end{array}$} & $\begin{array}{c}\text { The Value of the Final Index of } \\
\text { effectiveness of Cultural } \\
\text { Institutions of the Region, } E^{*}, \%\end{array}$ & \multicolumn{1}{|c|}{ The Number of Regions, \% } \\
\hline High & $E^{*} \geq 75$ & 28.21 \\
\hline Significant & $75<^{*} \leq 50$ & 48.72 \\
\hline Insignificant & $E^{*}<50$ & 23.08 \\
\hline
\end{tabular}

The problem of visualizing the obtained results is solved by constructing a ranking map of Russian regions according to the effectiveness level of cultural institutions presented in "Table IV" and "Fig. 1".

TABLE IV. THE FINAL INDEX OF EFFECTIVENESS $E^{*}, \%$

\begin{tabular}{|cc|}
\hline From & To \\
0.0 & 50.0 \\
51.0 & 74.0 \\
75.0 & 100.0 \\
\hline
\end{tabular}




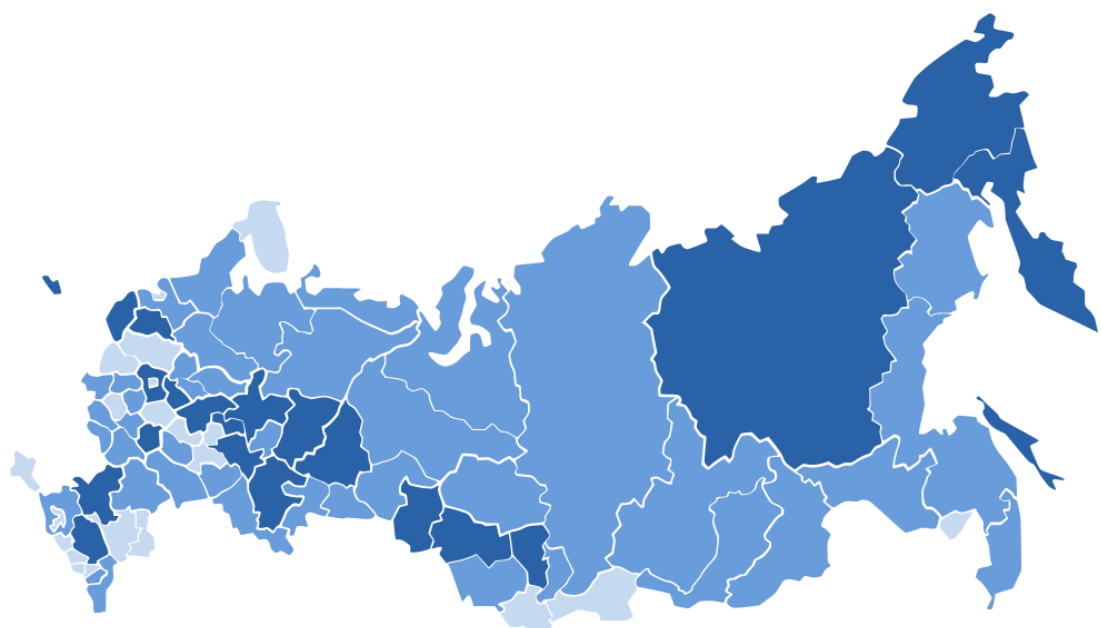

Fig. 1. The ranking map of Russian regions according to the effectiveness level of cultural institutions.

An important aspect of the study of the cultural industry is the evaluation of the relationship between the activities of cultural institutions and the economic development of the Russian Federation. The problem of correlation analysis is solved in this case with a large number of various indices traditionally used to evaluate the activities of cultural institutions of different types and a limited coverage of sample at the regional level. The integral index that comprehensively evaluates the activity of the most important types of cultural institutions in the regions makes it possible to identify the correlation dependence. The volume of gross regional product (GRP) for the constituent entities of the Russian Federation is considered in many cases as an index characterizing regional development. However, for the study of cultural sectors in 2018, the necessary information on GRP was not available at the time of preparation of the article. As an index that indirectly reflects the level of regional development, it is proposed to use the size of investments in fixed assets and use the increase in fixed asset formation in 2018 in percentage by 2017.

The analysis of the correlation between those indices does not suggest that there is a linear relationship between the activities of cultural institutions and the pace of economic development of the region during the period under review (Pearson correlation coefficient $r=-0.0829, p=0.470$ ).

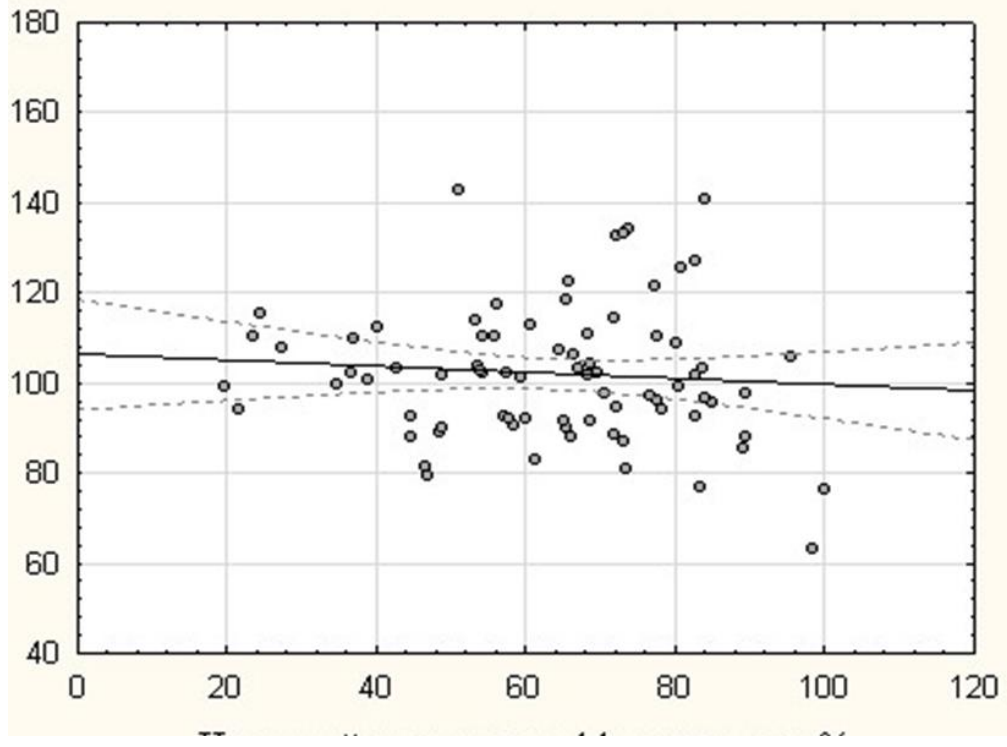

Fig. 2. Relationship between the final index of effectiveness of the cultural industry and the change in investment volume in fixed assets in 2018 .

a. The vertical scale - Fixed Asset Formation in 2018,\% by 2017, The horizontal scale - The Final Index of Effectiveness, $\%$ 
"Fig. 2" is a dispersion diagram illustrating the absence of a linear relationship between the integrated index of effectiveness of cultural institutions functioning at the regional level and the change in investment volume in fixed assets in 2018 .

\section{CONCLUSION}

The advantage of the proposed approach to constructing a rating model for evaluating of the regions lies in the possibility of ranking a large number of objects according to a set of interconnected indices characterizing resource allocation and the results of cultural institutions functioning at the regional level. Using the information entropy function to calculate the integrated rating enables to reduce subjectivity in determining the weighing coefficient of additive models and to increase the accuracy of ranking.

The evaluation of the impact of the cultural industry functioning on the economic growth of Russia was carried out with help of a constructed aggregated index of effectiveness of regional cultural institutions functioning. There is no linear correlation between the integrated index for cultural industry evaluation and the selected indices reflecting the economic development of the region.

The results of the study confirm the need to develop effective financing strategies for cultural institutions, to trigger new methods of extra budgetary financing [16] in the face of a decrease in solvent demand for services in the cultural industry and to use additional nonfinancial indices to evaluate the effectiveness of cultural institutions. It is necessary to expand the appliance of the algorithm for evaluation the effectiveness of regional systems of the cultural industry based on DEA methodology to other components of the cultural industry. The obtained research results make it possible to introduce an effective organizational and economic mechanism for the development of the cultural industry in the regions of the Russian Federation.

\section{References}

[1] Malshina N. A. The culture industry of the Russian Federation integrated service centres: regional aspect / Proceedings of the International Scientific Conference "Competitive, Sustainable and Secure Development of the Regional Economy: Response to Global Challenges" (CSSDRE 2018) URL:https://doi.org/10.2991/cssdre-18.2018.58

[2] Russia in numbers. 2018: Krat.stat.sat. / Rosstat. M., P 762018. 522 PP. URL: http://www.gks.ru/free_doc/doc_2018/rusfig/rus18.pdf

[3] Main information and computing center of the Ministry of culture of the Russian Federation UR L: https://stat.mkrf.ru/indicators/ (date of issue: 26.10.2019)
[4] Adorno T. W. Culture Industry reconsidered, in The Culture Idustry / Witkin R.W., Adorno on popular Culture. Cambridge: Polity, 2003. $385 \mathrm{p}$

[5] Bernstein J. M. Introduction to Adorno's the culture industry. London and New York. 2008. 210 p.

[6] Malshina N., Firsova A. Mechanisms of Innovative Projects Financing in the Culture Industry on the Basis of Public-private Partnership / Proceedings of the 3rd International Conference on Judicial, Administrative and Humanitarian Problems of State Structures and Economic Subjects (JAHP 2018). Series: Advances in Social Science, Education and Humanities Research (ASSEHR), vol. 252, p. 100-105.

[7] Held D. Introduction to Critical Theory Horkheimer to Habermas / T. W. Adorno. How to look at televisDion, in the Culture industry. University of California Press. 1980, p. 94-96

[8] Creative Industries // UNESCO. URL: http://www.unesco.org/new/en/culture/themes/creativity/creativ e-industries/ (date of issue: 26.10.2019)

[9] Firsova A., Chernyshova G. Analysis of efficiency of regional innovation systems taking into account the financing structure. Proceedings of the International Scientific Conference "Competitive, Sustainable and Secure Development of the Regional Economy: Response to Global Challenges" (CSSDRE 2018), Series: AEBMR, 2018, vol. 39, pp. 417-422.

[10] Loseva O. V. Development of methodology of estimation of innovative capital of the region / / Innovative development of economy. 2017. No. 5 (41). p. 27-35

[11] Cooper W. W., Seiford L. M., Tone K. Introduction to Data Envelopment Analysis and Its Uses. New York, Springer US 2006. 354 p. DOI: https://doi.org/10.1007/0-387-29122-9

[12] Zhu J. Data Envelopment analysis: Handbook of Empirical Studies and Applications N.Y.: Springer, 2016, 587 p.

[13] Cheng G., Zervopoulos P. D. Estimating the technical efficiency of health care systems: A cross-country comparison using the directional distance function. European Journal of Operational Research, 2014, 238(3), pp. 899-910.

[14] Shannon K. Works on information theory and Cybernetics / K Shannon. Moscow: Publishing house of foreign literature, 1963. $830 \mathrm{PP}$.

[15] Zou Z., Yun Y., Sun J. Entropy method for determination of weight of evaluating indicators in fuzzy synthetic evaluation for water quality assessment. Journal of Environmental Sciences, 2006,18 (5), pp. 1020-1023.

[16] Malshina N., Firsova A. Mechanism of financing the project activities of the creative industries in the Russian Federation. Proceedings of the International Scientific Conference "Far East Con" (ISCFEC 2018). Series: AEBMR, 2018, vol. 47. pp. 11011104 